Research Article

\title{
Chronic alcohol use affects therapeutic steady state plasma drug concentrations of stavudine, lamivudine and nevirapine in HIV-infected patients during 9 months follow up period: WHO AUDIT tool application
}

\author{
Godfrey S. Bbosa ${ }^{1}$, David B. Kyegombe ${ }^{2}$, William W. Anokbonggo ${ }^{1}$, Muhammad Ntale ${ }^{3}$, \\ David Musoke ${ }^{4}$, John Odda ${ }^{1}$, Aloysius Lubega ${ }^{1}$, Jasper Ogwal-Okeng ${ }^{1}$
}

\begin{abstract}
${ }^{1}$ Department of Pharmacology and Therapeutics, Makerere University College of Health Sciences, Uganda ${ }^{2}$ Department of Pharmacology and Toxicology, Kampala International University School of Health Sciences, Busyenyi, Uganda

${ }^{3}$ Department of Chemistry, Makerere University College of Natural Sciences, Uganda

${ }^{4}$ Department of Pharmacology and Therapeutics, Gulu University Medical School, Uganda
\end{abstract}

Received: 10 July 2013

Accepted: 21 July 2013

*Correspondence to:

Dr. Godfrey S. Bbosa,

Email:

godfossa@yahoo.com/godfossa@gmail. com

(C) 2013 Bbosa GS et al. This is an openaccess article distributed under the terms of the Creative Commons Attribution Non-Commercial License, which permits unrestricted non-commercial use, distribution, and reproduction in any medium, provided the original work is properly cited.

\begin{abstract}
Chronic alcohol consumption is a common problem among the HIVinfected patients on HAART. The study determined the effect of chronic alcohol use on steady state plasma drug concentrations of stavudine (d4T), lamivudine (3TC) and nevirapine (NVP) in HIV-infected patients during the 9 months follow up period. It also determined whether there were some patients with undetectable plasma drug concentrations in their plasma during the follow up. A case control using repeated measures design with serial measurements model, where plasma drug concentrations were measured at 3 month intervals was used. Chronic alcohol-use using WHO AUDIT tool was used to screen patients. A total of 41 patients ( 21 alcohol group and 20 control group) were followed up for 9 months with blood sampling done at 3 month intervals. The Shimadzu Class-VPTM HPLC Chromatography data system version 6.1 equipment with UV detector was used to measure the plasma drug concentrations. Data was analyzed using SAS 2003 version 9.1 statistical package with repeated measures fixed the model and means were compared using the student t-test. The mean steady state plasma concentration of both $\mathrm{d} 4 \mathrm{~T}$ and $3 \mathrm{TC}$ in chronic alcohol use group were lower than in the control group all throughout the 9 months period of follow-up. The mean steady state plasma drug concentrations of NVP were higher in the alcohol group at 0 and 3 months and lower in the 6 and 9 months as compared to the control group. The mean total plasma NVP concentration was higher in the chronic alcohol group as compared to the control group and the difference was statistically significant $(\mathrm{p} \leq 0.05)$. However some patients had undetectable plasma drug concentrations despite of having $\geq 95 \%$ adherence rate. Chronic alcohol use by the HIV-infected patients lowers the steady state plasma drug concentrations of d4T, 3TC and NVP in patients.
\end{abstract}

Keywords: Chronic alcohol use, Therapeutic steady state plasma drug concentrations, HIV, d4T, 3TC, NVP

\section{INTRODUCTION}

Chronic alcohol use is a global problem. The World Health Organization (WHO) estimates that about 2 billion people worldwide consume alcoholic beverages and 76.3 million people experiences diagnosable alcohol use disorders. ${ }^{1-3}$ Alcohol mainly ethanol or ethyl alcohol is found in many alcoholic beverages such as wine, spirits, liquors, beers and traditional brew and it is by far the most abused drug for centuries in the different countries world over. ${ }^{4}$ In Uganda, alcohol consumption is a serious problem and is a widely accepted social drink in the cultural and ceremonial activities. ${ }^{5-7}$ Among the chronic alcohol consumers in Uganda are the HIV- 
infected patients on the highly active antiretroviral therapeutic (HAART) drugs like stavudine (d4T), lamivudine (3TC) and nevirapine (NVP) drug regimen. However the pharmacokinetics (absorption, distribution, metabolism and excretion - ADME) of these drugs can be affected by the use of chronic ethanol and its metabolites. Alcohol is metabolized by both the hepatic and extrahepatic enzyme systems. ${ }^{8}$ The most common extrahepatic metabolizing enzyme being alcohol dehydrogenase enzyme isoforms, aldehyde dehydrogenase enzyme isoforms and catalase found mainly in the gut wall in males and in the liver in females. ${ }^{8-10}$ Some of the hepatic microsomal ethanol oxidizing systems (MEOS) include cytochrome 2E1 (CYP2E1), CYP1A2 and CYP3A4 with CYP2E1 the main alcohol metaboliser in the liver. The activity of CYP2E1 may be induced or inhibited in some individuals especially in chronic alcohol consumption and it varies among people. ${ }^{8,9,11,12}$ There is a sex difference in alcohol metabolism where in males it is mainly metabolized in the gastrointestinal tract (GIT) while in females, metabolism occurs in the liver. ${ }^{8,9,11,13}$ The products of the alcohol metabolism affect the body's physiological processes especially the liver and the kidney that responsible for the elimination of drugs from the body and hence affecting the pharmacokinetics of d4T, 3TC and NVP drugs used by the patients. ${ }^{14,15}$ This may significantly affect the therapeutic steady state plasma drug concentrations (therapeutic window) available to suppress the HIV virus.

Stavudine is a nucleoside reverse transcriptase inhibitor (NRTI) and administered as $30 \mathrm{mg}$ every 12 hours. Its binding to serum proteins has been reported to be negligible over the concentration range of 0.01 to 11.4 $\mu \mathrm{g} / \mathrm{mL}$ and distributes equally between red blood cells and plasma. The therapeutic steady state plasma concentration of $\mathrm{d} 4 \mathrm{~T}$ in healthy volunteers has been reported be $0.09-0.68 \mu \mathrm{g} / \mathrm{ml}$. The mean terminal elimination half-life ranges $0.8-1.5$ hours in adults following single oral dose, and is independent of dose. About $40-50 \%$ of stavudine dose is reported to be excreted unchanged in urine and the remaining $60 \%$ is presumably eliminated by endogenous pathways. ${ }^{16-18,47}$ Lamivudine is also an NRTI, administered as $150 \mathrm{mg}$ twice daily. The steady state plasma concentration of lamivudine in healthy volunteers is reported to be 0.2 to 1.42 to $\mu \mathrm{g} / \mathrm{mL}$. About $70 \%$ to $80 \%$ is excreted unchanged in urine by the active cationic secretion via glomerular filtration and tubular secretion with minor metabolism. It has a mean terminal half-life of elimination of 5 to 7 hours with the intracellular half-life of the lamivudine 5'triphosphate, the active metabolite being 10.5 to 15.5 hours and 17 to 19 hours in HIV-1 and hepatitis B virus (HBV) infection and peripheral blood lymphocytes cell lines respectively. ${ }^{16-19,48}$ The nevirapine (NVP) is a nonnucleoside HIV-1 reverse transcriptase inhibitor (NNRTI) with a potent and selective inhibitor of the replication of a wide variety of HIV-1 strains in several cellular assays. ${ }^{16,17,19}$ Nevirapine is administered at a dose of $400 \mathrm{mg} /$ day in adults and has a therapeutic steady state plasma concentration of 5.3 to $11.7 \mu \mathrm{g} / \mathrm{mL}$ with a halflife of 25-30 hours following multiple dosing. More than $80 \%$ of a nevirapine dose is biotransformed via CYP450 oxidation to hydroxylated metabolites that are mainly excreted in urine as glucuronides. Only a small fraction of administered dose $(<3 \%)$ is excreted unchanged in the urine. The treatment with $200 \mathrm{mg}$ per day of nevirapine over a 2-week period results in CYP450 metabolic autoinduction of CYP3A and CYP2B6 pathways, as well as an increase in nevirapine apparent clearance and a decrease in nevirapine half-life from approximately 45 hours to 30 hours. $^{20-22,48,49}$

The concomitant use of ethanol by some HIV-infected patients on $\mathrm{d} 4 \mathrm{~T} / 3 \mathrm{TC} / \mathrm{NVP}$ drug regimen may lead to alcohol-drug interaction that can affect the steady state therapeutic plasma drug concentrations (therapeutic window). ${ }^{23}$ This may lead to either achieving the toxic levels of the individual drugs leading to increased toxicity or to the sub-therapeutic drug levels leading to therapeutic failure. Chronic use of ethanol and its metabolites can damage the liver and the kidney of the patients thus affecting the elimination of the d4T, 3TC and NVP drugs from the body and hence their therapeutic steady state plasma drug concentrations (therapeutic window). This leads to the drug toxicity that is possibly observed in many HIV-infected patients on chronic treatment with ARVs.

In the body, the accumulation of ethanol, its metabolites like acetaldehyde, reactive oxygen species ( $\mathrm{ROS}-\mathrm{O}_{2^{-}}$, $\mathrm{H}_{2} \mathrm{O}_{2}$ ) and other environmental factors like dietary foods can also trigger the induction of epigenetic (pharmacogenetic) mechanisms such as DNA (de)methylation, histone modifications like (de)acetylation, (de)methylation and (de)phosphorylation as well as the non-coding microRNAs (miRNAs). ${ }^{24-27}$ These mechanisms may alter the gene expression that encodes various CYP450 metabolizing enzymes, drug transporter proteins, transcription factors, drug targets and nuclear receptors thus influencing the individual's response to the drug administered ${ }^{24-26,28}$, thus leading to drug toxicity or subtherapeutic plasma drug concentrations or alteration of the therapeutic window. Also single-nucleotide polymorphisms (SNPs), may influence the individual response to the drugs by affecting the pharmacokinetics and pharmacodynamics drug properties and hence either delaying or facilitating the elimination of drugs from the body thus requiring individual's drug dosing determination. ${ }^{29-31}$ Also alcohol being a diuretic agent ${ }^{32-34}$, it may increase the elimination of the free drugs that are mainly excreted from the body through urine by the kidneys in unchanged form like stavudine and lamivudine. ${ }^{35-37}$ Also the quality of the drugs (fake and substandard) have been reported on the market and are administered to the patients and this may lead to sub-therapeutic plasma drug concentrations required to suppress the HIV virus replication. This also affects the therapeutic outcomes of the patients in terms 
of the HIV viral load and their $\mathrm{CD}^{+}$count. However, under normal circumstances of multiple drugs dosing of $\mathrm{d} 4 \mathrm{~T}, 3 \mathrm{TC}$ and NVP, after a loading dose, the patients are supposed to maintain a therapeutic steady state plasma drug concentrations that has to be maintained during the period of treatment such that at anytime of sampling the blood and analysis of the plasma drug concentrations, the therapeutic steady state plasma drug concentrations ranges are maintained. The steady state therapeutic drug concentrations (therapeutic window) of the d4T, 3TC and NVP may be affected by the chronic alcohol use (Table 1). The study determined the effect of chronic alcohol use by the HIV-infected patients on the therapeutic window of $\mathrm{d} 4 \mathrm{~T}, 3 \mathrm{TC}$ and NVP. It also determined whether there were some patients with undetectable plasma drug concentrations in their blood.

Table 1: Therapeutic steady state concentrations of d4T, 3TC and NVP. ${ }^{16,17,47-49}$

\begin{tabular}{|lll|}
\hline \multirow{2}{*}{ Drug } & \multicolumn{2}{l|}{ Therapeutic window } \\
\cline { 2 - 3 } & $\begin{array}{l}\text { Peak plasma } \\
\text { concentration } \\
(\mu \mathrm{g} / \mathrm{ml})\end{array}$ & $\begin{array}{l}\text { Trough } \\
\text { concentration } \\
(\mu \mathrm{g} / \mathrm{ml})\end{array}$ \\
\hline Stavudine & 0.68 & 0.09 \\
\hline Lamivudine & 1.42 & 0.2 \\
\hline Nevirapine & 11.7 & 5.3 \\
\hline
\end{tabular}

\section{METHODS}

\section{Study design}

The study was a case control study that used repeated measures design model and it was conducted on the HIVinfected patients who were exposed to chronic alcohol and at the same time, they were initiated on the $\mathrm{d} 4 \mathrm{~T} / 3 \mathrm{TC} / \mathrm{NVP}$ drug regimen [triomune 30 (lamivudine (3TC) $150 \mathrm{mg}$, nevirapine (NVP) $200 \mathrm{mg}$ and stavudine (d4T) $30 \mathrm{mg}$ tablets)] for the last 6 months. The drug regimen was selected because during the time of the study, it was one of the first line drug regimens available for the treatment of HIV-infected patients in the country. The d4T/3TC/NVP drug regimen was one of the first-line drug regimen used in the suppression of the HIV virus in the patients during the study period. The serial measurements model to quantify the plasma drug concentrations was used.

\section{Study site and population}

The study was conducted at St. Raphael of St Francis hospital, Nsambya, Private clinic and department of Pharmacology and Therapeutics pharmacokinetic laboratory. The hospital handles about 1,500 HIVinfected patients. A total of $41 \mathrm{HIV}$-infected patients who are on $\mathrm{d} 4 \mathrm{~T} / 3 \mathrm{TC} / \mathrm{NVP}$ drug regimen were recruited after being screened for chronic alcohol use using the WHO alcohol use disorder identification test (AUDIT) tool.

\section{Inclusion criteria}

All the HIV-infected patients who were included in this study were HIV positive, on d4T/3TC/NVP drug combination regimen for the last 6 months at the time of enrollment. The adherence rates of all the patients recruited were measured using the self-reporting adherence and the pill counts at scheduled visits and all had an adherence rate of above $95 \%$. This was to ensure that the patients were taking their drugs as per the prescription. Also those included were in the age range of 18 to 50 years old. In the test group, they were exposed to chronic alcohol use at the time of recruitment and during the 9 months follow up study period after initiation of the HAART treatment and in the control group, they were not exposed to any type of alcohol at all or for the past 6 to 12 months.

\section{Eligibility criteria and enrolment of study participants}

The study was conducted on the HIV-infected patients who were initiated on the $\mathrm{d} 4 \mathrm{~T} / 3 \mathrm{TC} / \mathrm{NVP}$ drug regimen for the past 6 months. At the time of enrollment, a total of $41 \mathrm{HIV} / \mathrm{AIDS}$ patients on regimen were screened for chronic alcohol use using the WHO Alcohol Use Disorder Identification Test (AUDIT) tool. The 20 patients (13 males and 7 females) were identified to consume alcohol chronically using the tool and were enrolled into the chronic alcohol use group after signing the consent forms. The 21 patients (17 males and 4 females) were identified by the tool as non-alcohol consumers by the tool and were enrolled in the control group after consent. The WHO AUDIT is currently an important tool which is non-invasive and it's routinely used worldwide to screen patients on chronic alcohol consumption. $^{38}$ The AUDIT tool has a set of 10 questions, each with responses and scores which the individuals responded to by self-reporting. A total score of 8-15 indicates hazardous alcohol use, 16-19 indicates alcohol use problem and scores above 20 indicates alcohol use dependence. ${ }^{38}$ All the patients recruited in the chronic alcohol group had a total score of above 8 according to the WHO AUDIT tool interpretation of the scores. The patients enrolled in the control group had a score value of less than 8 total scores. The HIV-infected patients in both the control and chronic alcohol exposed group were followed-up for 9 months starting from March 2008 to November 2008. Each patient was explained well about the study and the significance of carrying the study and any questions raised were answered. All those patients who accepted to participate in the study willingly and were ready to follow the study guidelines all through the 9 month period of follow up were recruited after signing the consent forms and those that breached it were excluded from the study but this didn't affect their healthcare services at the clinic. 


\section{Whole blood sample collection and plasma processing}

About $5 \mathrm{~mL}$ of whole venous blood samples from the patients were collected between $10 \mathrm{am}$ and $1 \mathrm{pm}$ on the day of sampling from cubital vein into a sterile vacutainer with EDTA as anticoagulant every 3 months for a period of $9(0,3,6$ and 9) months. The plasma samples were obtained by centrifuging the blood at $3000 \mathrm{rpm}$ for 5 minutes. The plasma was extracted into a clean cryovials and kept into a deep freezer at a temperature of $-70^{\circ} \mathrm{C}$ prior to plasma drug concentration determination.

\section{Plasma drug analysis procedures}

The individual d4T, 3TC and NVP plasma drug concentrations were determined using the Shimadzu Class-VPTM HPLC Chromatography data system version 6.1 equipment using the UV detector using Notari et al. (2006) method. ${ }^{39}$

\section{Chemicals}

The pure stavudine, lamivudine and nevirapine that were used as standards were donated by a colleague from the department of Pharmacology and Therapeutics, Gulu University Medical School. Lamivudine was obtained from Iaf Biochem. Int./Glaxo Wellcome, nevirapine from Boehringer Ingelheim and stavudine from Bristol-Myers Squibb. All these drugs were of analytical grade and were used as standards and controls in the study. The acetonitrile and methanol were purchased from $\mathrm{BDH}$ chemicals and distributors representative company in Uganda. The $\mathrm{KH}_{2} \mathrm{PO}_{4}$ was a donated by a colleague from the department of Chemistry, Makerere University. All the reagents that were used were of HPLC grade. The distilled water and de-ionized water were produced onsite. The blank plasma, free of any drug was obtained from the Uganda Blood Bank (Nakasero, KampalaUganda).

\section{Chromatographic system}

The chromatographic system consisted of a Waters 600 pump and a Waters auto sample 717 PLUS equipped with a spectrophotometric UV-vis dual-wavelength system Waters 2487 set at 240 and $260 \mathrm{~nm}$ (Milford, MA, USA). The drug separation was performed at $24.0^{\circ} \mathrm{C}$ using analytical C18 Symmetry $^{\mathrm{TM}}$ column $(250 \mathrm{~mm} \times 4.6 \mathrm{~mm}$ I.D.) with a particle size of $5.0 \mu \mathrm{m}$ (Waters) equipped with a Waters Sentry guard column $(20 \times 3.9$ mmI.D. $)$ filled with the same packing material (Waters). The 'Millenium'software on the HPLC-UV instrument was used to process the data.

\section{Mobile phase solutions}

The mobile phase was composed of solution A ( $0.01 \mathrm{M}$ $\mathrm{KH}_{2} \mathrm{PO}_{4}$ ) and $\mathrm{B}$ (acetonitrile). Both solutions were degassed by sparging with helium. The injection volume was $20 \mu \mathrm{L}$. The mobile phase was delivered at a rate of $1.0 \mathrm{~mL} /$ minute and the gradient elution program was used (Table 2).

Table 2: Gradient elution program.

\begin{tabular}{|lllll|}
\hline $\begin{array}{l}\text { Time } \\
\text { (minutes) }\end{array}$ & $\begin{array}{l}\text { Flow } \\
(\mathrm{mL} / \mathrm{min})\end{array}$ & $\begin{array}{l}\mathrm{KH}_{2} \mathrm{PO}_{4} \\
\text { solution } \\
\mathrm{A}(\%)\end{array}$ & $\begin{array}{l}\text { Acetonitrile } \\
\text { solution B (\%) }\end{array}$ & $\mathrm{pH}$ \\
\hline 0 & 1 & 94 & 6 & 5.0 \\
\hline 10 & 1 & 30 & 70 & 4.5 \\
\hline 15 & 1 & 94 & 6 & 4.5 \\
\hline 20 & 1 & 94 & 6 & 4.5 \\
\hline 25 & 1 & 0 & 100 & - \\
\hline
\end{tabular}

Preparation of the stock, working, and blank plasma
solutions

Stock solutions of lamividine, nevirapine and stavudine $(1.0 \mathrm{mg} / \mathrm{mL})$ were prepared by dissolving $5.0 \mathrm{mg}$ of each of the HIV drug in $5.0 \mathrm{~mL}$ of methanol. Stock solutions were appropriately diluted with methanol for the preparation of working solutions (final concentration ranging between 0.005 and $10 \mu \mathrm{g} / \mathrm{mL}$ ). The stavudine, lamivudine and nevirapine drug concentration in blank plasma calibration samples ranged between 0.005 and $10 \mu \mathrm{g} / \mathrm{mL}$. The blank plasma was used to mimic the patient plasma samples.

\section{Sample preparation}

The plasma samples that were extracted from the HIVinfected patients on $\mathrm{d} 4 \mathrm{~T} / 3 \mathrm{TC} / \mathrm{NVP}$ drug combination regimen were cleaned-up by off-line solid phase extraction (SPE) using Oasis HLB Cartridge 1 cc (30 mg) (Waters). The SPE cartridges were conditioned with $1.0 \mathrm{~mL}$ methanol followed by $1.0 \mathrm{~mL}$ water Milli-Q. One hundred microliters of methanol were added to $600 \mu \mathrm{L}$ of human plasma, the solution was vortexed for $1.0 \mathrm{~min}$ and centrifuged at $5200 \mathrm{rpm}$ for 15.0 minutes, at $24.0^{\circ} \mathrm{C}$. The supernatant (ca. $650 \mu \mathrm{L})$ was diluted by adding water Milli-Q (1.0 mL) and loaded in the cartridge. Then, cartridges were washed with $1.0 \mathrm{~mL}$ of $5 \%(\mathrm{v} / \mathrm{v})$ methanol in water Milli-Q. The analytes were eluted by washing cartridges with $550 \mu \mathrm{L} 0.01 \mathrm{MKH}_{2} \mathrm{PO}_{4}$ followed by $2.0 \mathrm{~mL}$ absolute methanol. The eluate was evaporated in a water bath at $36.0^{\circ} \mathrm{C}$ under a stream of nitrogen. The extracted sample was reconstituted with $100 \mu \mathrm{L}$ absolute methanol and transferred to an injection vial. The HPLC-UV detection at 240 and $260 \mathrm{~nm}$ and the gradient program was used for stavudine, lamivudine and nevirapine drug separation and concentration determination for each drug. 


\section{Calibration curves and recovery}

The calibration curves were established over the 0.05 , $0.1,0.5,1.0,5.0$ and $10 \mu \mathrm{g} / \mathrm{mL}$ range for lamivudine and nevirapine and $0.1,0.5,1.0,5.0$ and $10 \mu \mathrm{g} / \mathrm{mL}$ ranges for the stavudine. The absolute recovery of each of these drugs from plasma was obtained as the peak-area response of the processed samples, expressed as the percentage of the response of the drugs contained in the $20 \mu \mathrm{L}$ injection volume and not subjected to SPE. The average retention time used for $\mathrm{d} 4 \mathrm{~T}, 3 \mathrm{TC}$ and NVP drugs are shown in table 3 . The areas of the chromatogram peaks for the standards were used to make a standard calibration curve for each drug (Figure 1). The concentration of each drug in each patient's plasma sample was obtained by using the generated equation of the straight-line and the slope. The Microsoft excel was used to prepare the standard curve and the calculation of the plasma drug concentration of each drug in each plasma sample. The results of the plasma drug levels were compared with reference values obtained from literature.

Table 3: Average retention time of $\mathrm{d} 4 \mathrm{~T}, 3 \mathrm{TC}$ and NVP drugs used.

\begin{tabular}{|ll|}
\hline ARV drug & Average retention time \\
\hline Lamivudine & 5.02 \\
\hline Stavudine & 6.3 \\
\hline Nevirapine & 16.5 \\
\hline
\end{tabular}

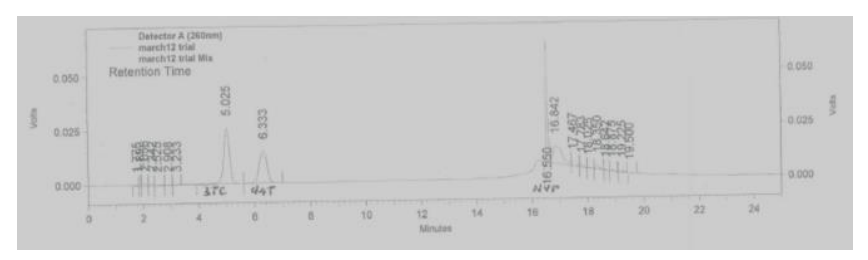

Figure 1: Chromatogram of d4T, 3TC and NVP.

\section{Data management and quality assurance}

All the samples from the patients were coded to ensure privacy and confidentiality throughout the study period. All the reagents used were of HPLC grade. All the samples analyzed were replicated. Standard operating procedures (SOP) were used all through the drug analysis in the laboratory. All the data collected and analyzed were entered in the Microsoft excel spread sheet for all the patients and was cleaned. The results were presented in form of tables and line graphs.

\section{Data analysis}

All the data was entered in the Microsoft excel and sorted using the chronic alcohol-use self-reporting WHO AUDIT tool method to produce data which were analyzed statistically. It was then imported into the SAS 2003 version 9.1 statistical package for statistical data analysis. The data was analyzed at $95 \%$ confidence interval. The repeated measures fixed model was used in the statistical data analysis. The t-test was used to compare the means of each plasma drug concentrations in the chronic alcohol use group and the control group at different time intervals of follow up. The outcome measures were the mean difference of the measured parameters between the chronic alcohol use and nonalcohol use basing on the chronic alcohol-use selfreporting WHO AUDIT tool method. The $\mathrm{p}$ value of less than 0.05 was regarded as statistically significant.

\section{Ethical consideration}

The research work was approved by the Faculty of Medicine Higher degrees, Research and Ethics committee of Makerere University Institution Review Board (IRB) (IRB\#-2007-060), IRB of St. Raphael of St Francis hospital, Nsambya (no. IRB 03: 01/03/2008) where the study participants were recruited from and the Uganda National Council for Science and Technology (UNCST) (no. HS 387), a government body that oversee all the research activities done in the country. All the study participants recruited into the study were each duly explained the details of the study and then screened for their eligibility to participate in the study. They were required to consent. They were given study code numbers which were used all through the study period in order to protect their privacy and confidentiality. Their names or any identifier were not used anywhere in the study.

\section{RESULTS}

The d4T, 3TC and NVP plasma drug concentrations were analyzed using the HPLC -UV detectors to produce a chromatogram (Figure 1). The effect of chronic alcohol use on the therapeutic steady state plasma drug concentrations of d4T, 3TC and NVP in the HIV-infected patients on $\mathrm{d} 4 \mathrm{~T} / 3 \mathrm{TC} / \mathrm{NVP}$ drug regimen was determined during the 9 months period of follow up. The results show that the mean d4T plasma drug concentrations in the chronic alcohol-use group were lower than in the control group. In both groups, the mean d4T plasma drug concentrations were above the normal therapeutic steady state values ranging from the 0.09 to $0.68 \mu \mathrm{g} / \mathrm{ml}$. Though, however in the 6 month of the follow up, the mean $\mathrm{d} 4 \mathrm{~T}$ plasma drug concentrations in the control group were observed to increase as compared to the chronic alcoholuse group (Table 4 and Figure 2). The mean 3TC plasma drug concentrations in the control group were also lower than in the chronic alcohol-use group. However, the 
values were higher than the normal therapeutic steady state 3TC plasma drug concentrations of $0.2-1.42 \mu \mathrm{g} / \mathrm{ml}$. The mean NVP plasma drug concentrations in the chronic alcohol-use group were also lower than in control group throughout the 9 month period of follow up. However the NVP plasma drug levels in both groups were within the normal therapeutic steady state plasma drug concentrations of 5.3-11.7 $\mu \mathrm{g} / \mathrm{ml}$. It was also observed that at the 6 month follow up, the d4T, 3TC and NVP in the control group, the concentrations tend to increase whereas in the chronic alcohol-use group the values tend to decrease in the same month and then after which they returned to the normal trend of the 0,3 and 9 month. In the table 5 , it shows the comparison of the mean plasma drug concentrations of $\mathrm{d} 4 \mathrm{~T}, 3 \mathrm{TC}$ and NVP in both the chronic alcohol-use and control groups. The mean d4T plasma drug concentrations were higher in the control group as compared to the chronic alcohol-use group. There was no significant difference $(p>0.05)$ in mean $d 4 T$ plasma drug concentrations for all the drugs at different time interval in both groups. However, similar trend was observed for the 3TC. The NVP mean plasma drug concentrations was higher in the chronic alcohol-use group as compared to the control group and there was significant difference $(\mathrm{p}=0.049)$ between the 2 groups. The results show some patients reported to have an adherence rate of above $95 \%$ were observed to have no detectable drug concentrations in their plasma (Table 6). For the $\mathrm{d} 4 \mathrm{~T}, 14.3 \%$ of the patients had no detectable plasma drug concentrations in their plasma in the 0 and 3 month period of follow up. In the 6 month, it was $15.8 \%$ and $11.1 \%$ in the 9 month of the follow up in the control group. In the chronic alcohol-use group, it was 5\% in both the 0 and 3 month and $15 \%$ in the 6 month and $22.2 \%$ in the 9 month. For the 3TC, all the patients were observed to have detectable plasma drug concentrations in their blood in both the chronic alcohol-use and control group. For the NVP, all the patients in the chronic alcohol-use group had detectable plasma drug concentrations in their blood circulation while in the control group, $4.8 \%$ had no detectable plasma drug concentrations in the 0 and 3 month follow up. In the 6 month, all the patients had detectable plasma drug concentrations in their plasma while in the 9 month of follow up, $5.6 \%$ had no detectable drug plasma concentrations in the control group.

Table 4: Effect of chronic alcohol consumption on the mean steady state d4T, 3TC and NVP plasma drug concentrations in alcohol-use self reporting during the 9 month follow-up period.

\begin{tabular}{|c|c|c|c|c|c|c|}
\hline \multirow{2}{*}{\multicolumn{2}{|c|}{ Mean plasma drug levels }} & \multicolumn{4}{|c|}{ Time of follow-up (months) } & \multirow{2}{*}{$\begin{array}{l}\text { Therapeutic } \\
\text { window }\end{array}$} \\
\hline & & 0 & 3 & 6 & 9 & \\
\hline \multirow{2}{*}{$\begin{array}{l}\mathrm{d} 4 \mathrm{~T} \pm \mathrm{SE} \\
(\mu \mathrm{g} / \mathrm{mL})\end{array}$} & Control & $0.89 \pm 1.09$ & $0.91 \pm 1.09$ & $2.68 \pm 5.2$ & $1.13 \pm 0.85$ & \multirow{2}{*}{$0.09-0.68$} \\
\hline & Alcohol & $0.74 \pm 0.31$ & $0.76 \pm 0.31$ & $0.91 \pm 0.84$ & $0.88 \pm 1.2$ & \\
\hline \multicolumn{2}{|l|}{$p$-value } & 0.40 & 0.42 & 0.16 & 0.52 & \\
\hline \multirow{2}{*}{$\begin{array}{l}3 \mathrm{TC} \pm \mathrm{SE} \\
(\mu \mathrm{g} / \mathrm{mL})\end{array}$} & Control & $3.62 \pm 2.75$ & $3.7 \pm 2.82$ & $4.74 \pm 2.06$ & $4.36 \pm 3.3$ & \multirow{2}{*}{$0.2-1.42$} \\
\hline & Alcohol & $3.48 \pm 0.98$ & $3.58 \pm 0.9$ & $3.31 \pm 1.09$ & $4.18 \pm 3.34$ & \\
\hline \multicolumn{2}{|l|}{$p$-value } & 0.68 & 0.67 & 0.07 & 0.85 & \\
\hline \multirow{2}{*}{$\begin{array}{l}\mathrm{NVP} \pm \mathrm{SE} \\
(\mu \mathrm{g} / \mathrm{mL})\end{array}$} & Control & $5.7 \pm 2.35$ & $5.92 \pm 2.4$ & $6.6 \pm 3.7$ & $6.11 \pm 7.08$ & \multirow{2}{*}{$5.3-11.7$} \\
\hline & Alcohol & $6.46 \pm 2.93$ & $6.82 \pm 2.9$ & $5.76 \pm 1.87$ & $5.96 \pm 2.32$ & \\
\hline \multicolumn{2}{|l|}{$p$-value } & 0.58 & 0.57 & 0.61 & 0.91 & \\
\hline
\end{tabular}

SE: standard error; d4T: stavudine; 3TC: lamivudine; NVP: nevirapine 


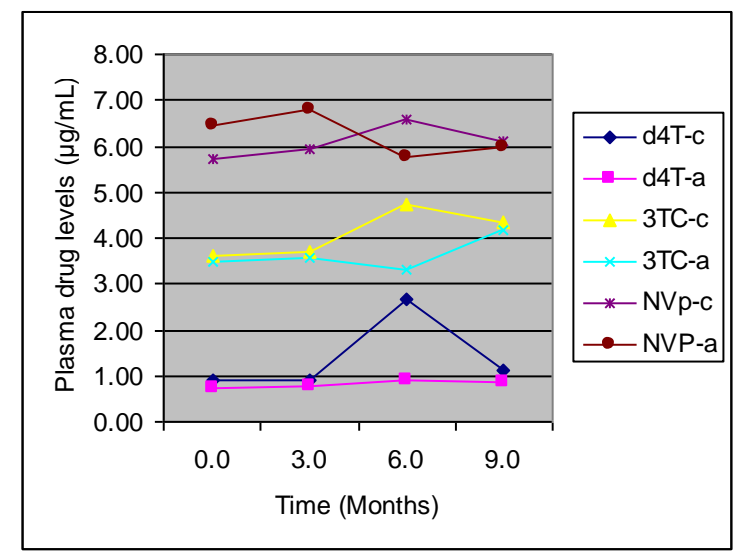

Figure 2: Variation of the mean d4T, 3TC and NVP steady state plasma drug concentrations with time for both chronic alcohol-use and control groups using alcohol-use self reported method.

d4T-c: d4T in control group; d4T-a: d4T in chronic alcohol; 3TC-c: 3TC in control; 3TC-a: 3TC in chronic alcohol; NVP-c: NVP in control; NVP-a: NVP in chronic alcohol

Table 5: Comparison of mean d4T, 3TC and NVP plasma drug concentrations for alcohol-use selfreporting method.

\begin{tabular}{|llll|}
\hline $\begin{array}{l}\text { Mean drug } \\
\text { levels }\end{array}$ & $\begin{array}{l}\text { Control } \\
\text { group }\end{array}$ & $\begin{array}{l}\text { Chronic alcohol } \\
\text { consumption }\end{array}$ & $\begin{array}{l}\mathbf{p} \\
\text { value }\end{array}$ \\
\hline $\begin{array}{l}\mathrm{d} 4 \mathrm{~T} \pm \mathrm{SE} \\
(\mu \mathrm{g} / \mathrm{mL})\end{array}$ & $1.17 \pm 0.27$ & $0.92 \pm 0.25$ & 0.525 \\
\hline $\begin{array}{l}3 \mathrm{TC} \pm \mathrm{SE} \\
(\mu \mathrm{g} / \mathrm{mL})\end{array}$ & $4.24 \pm 0.84$ & $4.3 \pm 0.79$ & 0.959 \\
\hline $\begin{array}{l}\mathrm{NVP} \pm \mathrm{SE} \\
(\mu \mathrm{g} / \mathrm{mL})\end{array}$ & $4.5 \pm 0.55$ & $5.96 \pm 0.51$ & 0.049 \\
\hline
\end{tabular}

Table 6: Patients with undetectable d4T, 3TC and NVP plasma drug concentrations in their blood.

\begin{tabular}{|llllll|}
\hline \multirow{2}{*}{ ARV drug } & & \multicolumn{4}{l}{$\begin{array}{l}\text { \% of HIV-infected patients with } \\
\text { no detectable plasma drug levels } \\
\text { during the time of follow-up } \\
\text { (months) }\end{array}$} \\
\cline { 3 - 7 } & & 3 & 6 & 9 \\
\hline \multirow{2}{*}{ d4T } & Control & $\begin{array}{l}14.3 \\
(\mathrm{n}=3)\end{array}$ & $\begin{array}{l}10.0 \\
(\mathrm{n}=2)\end{array}$ & $\begin{array}{l}15.8 \\
(\mathrm{n}=3)\end{array}$ & $\begin{array}{l}11.1 \\
(\mathrm{n}=2)\end{array}$ \\
\cline { 2 - 7 } & Alcohol & $\begin{array}{l}5.0 \\
(\mathrm{n}=1)\end{array}$ & $\begin{array}{l}10.0 \\
(\mathrm{n}=2)\end{array}$ & $\begin{array}{l}15.0 \\
(\mathrm{n}=3)\end{array}$ & $\begin{array}{l}22.2 \\
(\mathrm{n}=4)\end{array}$ \\
\hline \multirow{3}{*}{$3 \mathrm{TC}$} & Control & 0.0 & 0.0 & 0.0 & 0.0 \\
\cline { 2 - 6 } & Alcohol & 0.0 & 0.0 & 0.0 & 0.0 \\
\hline \multirow{2}{*}{ NVP } & Control & $\begin{array}{l}4.8 \\
(\mathrm{n}=1)\end{array}$ & 0.0 & 0.0 & $\begin{array}{l}5.6 \\
(\mathrm{n}=1)\end{array}$ \\
\cline { 2 - 6 } & Alcohol & 0.0 & $\begin{array}{l}5.0 \\
(\mathrm{n}=1)\end{array}$ & 0.0 & 0.0 \\
\hline
\end{tabular}

\section{DISCUSSION}

The results in the table 4 show that the steady state plasma drug concentrations of $\mathrm{d} 4 \mathrm{~T}$ and $3 \mathrm{TC}$ were higher than the therapeutic steady state plasma drug concentration reference ranges of $0.09-0.68 \mu \mathrm{g} / \mathrm{ml}$ and $0.2-1.42 \mu \mathrm{g} / \mathrm{ml}$ respectively in both the chronic alcohol use and control group throughout the 9 month follow up period. The high plasma drug concentration of $\mathrm{d} 4 \mathrm{~T}$ and 3TC could be due to the drug formulation problem where pharmaceutical companies may have more active drug ingredients being incorporated in the drug during the compounding above the recommended pharmacopoeia standards. $^{40,41}$ This leads to the drug toxicity possibly observed in the HIV-infected patients on prolonged treatment thus requiring instituting of the therapeutic drug monitoring and consideration of the personalized medicine during the treatment of the patients. Also since the patients are on prolonged treatment and together with the high steady state plasma drug concentrations of $\mathrm{d} 4 \mathrm{~T}$ and 3TC above the reference ranges, these causes the liver and kidney toxicity and yet these organs are responsible for the elimination of the these drugs from the body and hence causing their accumulation due to the delay in their elimination thus leading to the observed effect in the study. ${ }^{42,43}$ However the steady state plasma drug concentrations of $\mathrm{d} 4 \mathrm{~T}$ and $3 \mathrm{TC}$ in the chronic alcohol use group were lower than the control group and this could be due to the diuretic effect of ethanol and its metabolites since these drugs undergo $80 \%$ excretion as free drug in unchanged form of which ethanol facilitates this process of elimination leading to the observed effects. $^{29-31,44}$ Also the activation of the epigenetic mechanisms by alcohol may lead to gene expression of the of the drug transporters that facilitate the elimination of the drugs in urine from the body thus requiring consideration of individualized medicine..$^{29-31,44}$ The NVP steady state plasma drug concentration was variable during the 9 months follow up period. It was higher in chronic alcohol group at 0 and 3 month of follow up and lowers in the 6 and 9 months. It was possible that at 0 and 3 month, NVP suppressed the CYP450 metabolizing enzyme and then at the 6 and 9 month, the ethanol metabolites activated the metabolizing system thus causing the variation in mean steady state plasma drug concentrations of NVP in the patients. NVP is mainly eliminated from the body by CYP450 enzyme metabolism especially CYP3A and CYP2B6 pathways and these isoenzymes can also be autoinduced by ethanol thus facilitating the clearance of NVP from the plasma.

The observed high plasma drug levels of $\mathrm{d} 4 \mathrm{~T}$ and 3TC in some patients could also be due to the suppressed epigenetic mechanisms by the drugs themselves (nucleoside and non-nucleoside analogues that are DNA methyltransferases (DNMTs) inhibitors) and as well as exposure to other environmental factors like the alcohol, herbs and dietary substances by the individual patients that may suppress gene expression that encodes for the CYP450 drug metabolizing enzymes especially for NVP 
that undergo CYP450 metabolism thus leading to the failure of drug transport from blood circulation to tissues. ${ }^{24-27,44,45}$ Also SNPs may be triggered by ethanol and its metabolites and other environmental exposures by the patients such as herbs and foods may have contributed to the observed high $\mathrm{d} 4 \mathrm{~T}$ and 3TC plasma drug levels by suppressing the CYP450 and drug transport system thus delaying the elimination of the drugs from the body in some patients. ${ }^{29-31,44}$ These result in accumulation of the $\mathrm{d} 4 \mathrm{~T}$ and $3 \mathrm{TC}$ drugs in blood circulation observed in the study and this could be the reason to why most of these patients experience toxicity after prolonged period off treatment. However, the mean total steady state plasma drug concentrations of d4T, 3TC and NVP (Table 5) in both the chronic alcohol use group and the control group were varying and this could be due to the contribution of the observed undetectable plasma drug concentrations in some patients that could have affected the mean total steady state plasma drug concentrations in the patients.

\section{Undetectable plasma drug concentration in the HIV- infected patients}

In the control group, the undetectable $\mathrm{d} 4 \mathrm{~T}$ and NVP plasma drug concentration could be due to the poor quality (fake and substandard) drugs which the patients may have been exposed to during their treatment in which there were no active ingredients in the drug during the drug formulation by the pharmaceutical companies. $^{40,41}$ It may also be due to the effect of adherence in which the methods used (pill count at scheduled visits and self reporting) are not sensitive enough to detect any patients who were not adhering to the treatment leading to missed doses that affects the steady state plasma drug concentrations in the patients as observed in the study. In the chronic alcohol use group, other than the poor quality of the drugs and poor adherence, ethanol and its metabolites may contribute to a significant effect on the rapid elimination especially excretion of $\mathrm{d} 4 \mathrm{~T}$ and $3 \mathrm{TC}$ since $80 \%$ of these drugs are excreted as free drugs in urine. The observed undetectable d4T and NVP plasma drug levels in some patients in both the alcohol group and the control group may be due to the activation of the epigenetic mechanisms by some environmental factors such as dietary and herbal substances, ethanol and its metabolites that may increase the over expression of the genes that encode the CYP450 metabolizing enzymes and the drug transporter proteins that cause rapid elimination of drugs from the body. ${ }^{27,29-31}$ In alcohol group, ROS may have played a significant role in gene expression. In the control group, the undetectable plasma levels may also be due to SNPs as a result of mutations of the genetic code leading to over expression of CYP450 enzyme systems and transport proteins leading to rapid elimination of the $\mathrm{d} 4 \mathrm{~T}$ and NVP drugs from the body observed in the group. ${ }^{29-31}$ Also alcohol has a diuretic effect that inhibits the secretion of antidiuretic hormone (ADH) from both the supraoptic and paraventricular nuclei of the hypothalamus ${ }^{33,34}$ and this increase the excretion of the $\mathrm{d} 4 \mathrm{~T}$ and NVP free drugs in urine in unchanged form thus lowering the drugs half-lives. ${ }^{10,32,36,46}$ The diuretic effect of alcohol ${ }^{32,33}$ leads to the continued excretion of the $\mathrm{d} 4 \mathrm{~T}$ drugs as a free drug in urine that may lead to the undetectable levels as observed. ${ }^{10,43}$ These processes can lead to the sub-therapeutic plasma drug concentrations that cannot suppress HIV virus thus promoting the emergence of resistance, increase in the viral load and therapeutic failures. However, on the other hand, poor quality drugs, especially the drugs have no active ingredient could lead to undetectable plasma drug concentrations in circulation as observed in the patients. And if there too much active ingredients during formulation, toxicity may be a problem since patients will be operating in toxic drug concentrations ranges as observed in the study.

\section{CONCLUSION}

Chronic alcohol use, HIV disease and d4T, 3TC and NVP interact and affect the therapeutic steady state plasma drug concentrations in the HIV-infected patients. Ethanol and the accumulation of its metabolites in the body can damage the kidney and the liver that eliminate drugs from the body thus affecting the therapeutic steady state plasma drug concentration leading to the observed high levels of the drugs above the reference ranges. The undetectable $\mathrm{d} 4 \mathrm{~T}$ and NVP plasma drug concentrations in some patients may be attributable to poor adherence and poor quality drugs and these affect the therapeutic steady state plasma drugs levels that in turn affect the therapeutic outcome and recovery of the patients.

\section{ACKNOWLEDGEMENTS}

We would like to thank the following individuals who greatly contributed to the success of this work and without them, it would have been impossible to do this study. We want to thank Mr. Gordon Ewa in the Dept of Pharmacology and Therapeutics, Makerere University College of Health Sciences and Mr. Apollo Mugisha from the Clinical Chemistry Laboratory in National Referral Hospital Mulago Complex for their technical assistance in analyzing the samples. We want to thank Sr. Justine Birungi, Sr. Plaxeda, Sr. Namugosa, Sr. Jesca and Dr. Kayima from the St. Raphael of St Francis hospital, Nsambya, Private clinic who assisted us a lot in the recruitment of the subjects and the collection of blood samples from the patients. We want to thank the Director of St. Raphael of St Francis hospital, Nsambya and the Dr. Pius Okong, the chairman of IRB of the hospital for allowing us to conduct this study in the hospital. We want to thank Dr. Norah Mwebaza and Mr. Dan Kibuule of the Dept of Pharmacology and Therapeutics, Makerere University College of Health Sciences for their scientic support in the study.

\author{
Funding: None \\ Conflict of interest: None declared
}


Ethics approval: Approved by the local ethical committee [Faculty of Medicine Higher degrees, Research and Ethics committee of Makerere University Institution Review Board (IRB) (IRB\#-2007-060), IRB of St. Raphael of St Francis hospital, Nsambya (no. IRB 03: 01/03/2008) where the study participants were recruited from and the Uganda National Council for Science and Technology (UNCST)(no. HS 387)]

\section{REFERENCES}

1. GENACIS, Alcohol, Gender and Drinking Problems:Perspectives from Low and Middle Income Countries. Geneva, Switzerland. World Health Organization 2005. p. 2-241.

2. WHO, Global Status Report on Alcohol 2004. 2004: Geneva, Switzerland.

3. WHO, Alcohol and Injury in Emergency Department: Summary of the Report from the WHO Collaborative Study on Alcohol and Injuries. WHO Library Cataloguing-in-Publication Data, 2007: p. 111.

4. Micheal G. Alcohol health issues related to alcohol consumption. The place of alcohol in human culture, 1996: p. 1-22.

5. Kafuko, A. and P. Bukuluki, Qualitative research in Uganda on knowledge, attitude and practices concerning alcohol. 2008, USAID, Health Communication, YEAH and Afford: Corporate Agreement number 617-A-00-07-00005-00.

6. Lwanga-Ntale, C., Drinking into deeper poverty: The new frontier for Chronic Poverty in Uganda. Chronic Poverty Research Center: Development Research and Training. Policy Brief No.1/2007., 2007.

7. YEAH, Alcohol Consumption in Uganda: Literature Review. (Young Empowered and Health -YEAH) http://www.yeahuganda.org/research/AlcoholConsu mption.pdf (Accessed on 22/07/09). 2007.

8. Zakhari, S., Overview: How is alcohol metabolised by the body? The Journal of the National Institute on Alcohol Abuse and Alcoholism., 2006. 29(4): p. 245-252.

9. Edenberg, H.J., The role of alcohol dehydrogenase and aldehyde dehydrogenase variants:The genetics of alcohol metabolism. The Journal of the National Institute on Alcohol Abuse and Alcoholism., 2007. 30(1): p. 5-12.

10. Fleming, M., S.J. Mihic, and R.A. Harris, Ethanol. Goodman Gilman's, the pharmacological basis of therapeutics. McGraw-Hill Medical publishing Division, New York. 10th ed. 2001(18): p. 429-442.

11. Moore, S., et al., Variations in alcohol-metabolizing enzymes in people of East India and African descent from Trinidad and Tobago. The Journal of the National Institute on Alcohol Abuse and Alcoholism., 2007. 30(1): p. 28-30.

12. Quertemont, E. and V. Didone, Role of acetaldyde in mediating the Pharmacological and Behavioral effects of alcohol. The Journal of the National
Institute on Alcohol Abuse and Alcoholism., 2006. 29(4): p. 258-264.

13. Gore, K.A., R.J. Harris, and J.M. Firestone, Differences in male and female alcohol consumption. American Sociological Association Annual Meetings, August 14-17, San Francisco, CA 2008. USA. Allacademic Research journal, 2008: p. $1-20$.

14. Orrick, J.J., Antiretroviral drug interactions. Infectious Diseases: HIV/AIDS Primary care guide, Florida Aids Education and Training Centre, University of Florida. , 2002. 7: p. 69-81.

15. Scott, D.M. and R.E. Taylor, Health-related effects of genetic variations of alcohol-metabolising enzymes in African Americans. The Journal of the National Institute on Alcohol Abuse and Alcoholism., 2007. 30(1): p. 18-20.

16. Hoetelmans, R.M.W., Clinical Pharmacokinetics of Antiretroviral Drugs. AIDS Reviews., 1999. 1: p. 167-178.

17. L'hommea, R.l.F.A., et al., Nevirapine, stavudine and lamivudine pharmacokinetics in African children on paediatric fixed-dose combination tablets. AIDS. 2008 Wolters Kluwer Health Lippincott Williams \& Wilkins., 2008. 22: p. 557565.

18. FDA, AIDSinfo Drug Database: Offering on HIV/AIDS Treatment, Prevention and Research. AIDSinfo, 2013: p. http://aidsinfo.nih.gov/drugs/43/stavudine/0/professi onal (Cited on July 2013).

19. Tremoulet, A.H., et al., Population Pharmacokinetics of Lamivudine in Human Immunodeficiency Virus-Exposed and -Infected Infants. Antimicrobial agents and Chemotherapy. December. 2007. , 2007. 51(12): p. 4297-4302.

20. Belle, D.J. and H. Singh, Genetic Factors in Drug Metabolism. American Family Physician, 2008. 77(11): p. 1553-1560.

21. Krishna, D.R. and M.S. Shekar, Cytochrome P450 3A: Genetic polymorphisms and interethnic differences. Methods and Findings in Experimental Clinical Pharmacology, 2005. 27(8): p. 559.

22. Penzak, S.R., et al., Cytochrome P450 2B6 (CYP2B6) G516T influences nevirapine plasma concentrations in $\mathrm{HIV}$-infected patients in Uganda. HIV Medicine 2007: British HIV Association., 2007. 8: p. 86-91.

23. Bartlett, J.G. and J.E. Gallant, Medical Management of HIV Infection. Johns Hopkins University School of Medicine. Johns Hopkins Medicine Health Publishing Business Group. Baltimore, USA.20052006. , 2006.

24. Chuang, J.C. and P.A. Jones, Epigenetics and MicroRNAs. Pediatric Research, 2007. 61(5): p. 24R-29R. DOI: 10.1203/pdr.0b013e3180457684.

25. Lim, S.O., et al., Epigenetic changes induced by reactive oxygen species in hepatocellular carcinoma: methylation of the E-cadherin promoter Gastroenterology, 2008. 135: p. 2128-2140. 
26. Mathers, J.C., G. Strathdee, and C.L. Relton, Induction of epigenetic alterations by dietary and other environmental factors. Advances in Genetics, 2010. 71: p. 3-39.

27. Starkman, B.G., A.J. Sakharker, and S.C. Pandey, Epigenetics - Beyond the Genome in Alcoholism. Alcohol Research: Current Reviews. The Journal of the National Institute on Alcohol Abuse and Alcoholism, 2012. 34(3): p. 293-304.

28. Singh, S. and S. Li, Epigenetic Effects of Environmental Chemicals Bisphenol A and Phthalates. International Journal of Molecular Sciences, 2012. 13: p. 10143-10153; doi:10.3390/ijms130810143.

29. Evans, W.E. and H.L. McLeod, Pharmacogenomics - Drug Disposition, Drug Targets, and Side Effects. The New England Journal of Medicine, 2003. 348(6): p. 538-549.

30. Flaherty, D.K., Single Nucleotide Polymorphisms, Drug Metabolism and Untoward Health Effects. Journal of Medical and Biological Sciences, 2007. 1(2): p. 1-8.

31. Srivastava, P., Drug Metabolism and Individualized Medicine. Current Drug Metabolism, 2003. 4: p. 33 44.

32. Epstein, M., Alcohol's Impact on Kidney Function. Alcohol Health and Research World, 1997. 21(1): p. 84-93.

33. Heringlake, M., et al., The effects of ethanol and vasopressin on renal function in the isolated perfused rat kidney. Applied Cardiopulmonary Pathophysiology, 2011. 15: p. 24-28.

34. Vella, D.L. and D. Cameron-Smith, Alcohol, Athletic Performance and Recovery. Nutrients, 2010. 2: p. 781-789; doi:10.3390/nu2080781.

35. Brunton, L.L., J.S. Lazo, and K.L. Parker, Antiretroviral agents and treatment of HIV infection. Goodman and Gilman's The Pharmacological Basis of Therapeutics. 11th edition. 2006: p. 1273-1309.

36. Ferreira, M.P. and D. Willoughby, Alcohol Consumption: the good, the bad and the indifferent. Journal of Applied Physiology, Nutrition and Metabolism., 2007. 33: p. 12-20.

37. Triplit, C., Drug Interactions of Medications Commonly Used in Diabetes. Diabetes Spectrum, 2006. 19(4): p. 202-211.

38. Babor, T.F., et al., The Alcohol Use Disorders Identification Test (AUDIT) Manual: Guidelines for Use in Primary Care. Second Edition. Department of Mental Health and Substance Dependence. World
Health Organization 2001. WHO/MSD/MSB/01.6a., 2001: p. 4-32.

39. Notari, S., et al., Simultaneous determination of 16 anti-HIV drugs in human plasma by highperformance liquid chromatography. Journal of Chromatography B, 2006. 831: p. 258-266.

40. Gautam, C.S., A. Utreja, and G.L. Singal, Singal, Spurious and counterfeit drugs: a growing industry in the developing world Postgraduate Medical Journal, $2009 . \quad 86: \quad$ p. $251-256$. http://pmj.bmj.com/cgi/reprint/85/1003/251.pdf.

41. IMPACT, Counterfeit drugs kill. International Medical Products Anti-Counterfeiting Taskforce (IMPACT). World Health Organisation Drug Information, 2006. www.who.int/impact.

42. Aberg, J.A., Perspective of Drug-Drug Interactions With Newer Antiretroviral Agents: Topics in HIV Medicine. International AIDS Society-USA., 2008. 16(5): p. 146-149.

43. Weathermon, R. and D.W. Crabb, Alcohol and medication interactions. Alcohol Research and Health, 1999. 23(1): p. 40-54.

44. Gomez, A. and M. Ingelman-Sundberg, Pharmacoepigenetics: Its Role in Interindividual Differences in Drug Response. Discovery. Nature Publishing Group, 2009. 84(4): p. 426-430.

45. Kirk, H., et al., Botanicals as epigenetic modulators for mechanisms contributing to development of metabolic syndrome. Metabolism Clinical and Experimental 2008. 57(Suppl 1): p. S16-S23.

46. Grandjean, A.C., Water requirements, impinging factors, and recommended intakes. The Center for Human Nutrition, University of Nebraska, Omaha, Nebraska, USA, 2012. 3: p. 25-40. http://www.who.int/water_sanitation_health/dwq/nu trientschap3.pdf/March 2012.

47. Bristol-Myers-Squibb, Stavudine (Zerit): Patient Information Leaflet. Bristol-Myers Squibb. New Jersay, USA., 2009.

48. Sabo, J.P., et al., Pharmacokinetics of Nevirapine and Lamivudine in Patients with HIV-1 Infection. AAPS PharmSci (http://www.aapspharmsci.org). 2002. 2(1): p. 1-8.

49. Boehringer-Ingelheim, Nevirapine tablets. Boehringer Ingelheim Pharmaceuticals, Inc. CT, USA, 2008: p. 5-7.

doi:10.5455/2319-2003.ijbcp20131002

Cite this article as: Bbosa GS, Kyegombe DB, Anokbonggo WW, Ntale M, Musoke D, Odda J, Lubega A, Ogwal-Okeng J. Chronic alcohol use affects therapeutic steady state plasma drug concentrations of stavudine, lamivudine and nevirapine in HIV-infected patients during 9 months follow up period: WHO AUDIT tool application. Int $\mathbf{J}$ Basic Clin Pharmacol 2013;2:507-16. 